phase 111 , recently completed and as yet unpublished, will be important for assessing whether in Brazil, as in other countries, the prevalence of asthma in Brazil is on the rise.

\section{DIRCEU SOLÉ}

Professor Emeritus in the Allergy, Clinical Immunology and Rheumatology Sector of the Departament of Pediatrics at the Universidade Federal de São Paulo-Escola Paulista de Medicina

\section{REFERÊNCIAS}

1. Asher M1, Keil U, Anderson HR, Beasley R, Crane J, Martinez F et al. International study of asthma and allergies in childhood (ISAAC): rationale and methods. Eur Respir J 1995, 8: 483-91.

2. Solé D, Vanna AT, Yamada E, Rizzo MC, Naspitz CK. International study of asthma and allergies in childhood (1SAAC) written questionnaire: validation of the asthma component among Brazilian children. J lnvest Allergol Clin Immunol 1998; 8: 376-82.
3. Camelo-Nunes 1C. Validação construtiva do questionário escrito do "internacional study of asthma and allergies in childhood" (ISAAC) e caracterização da asma em adolescentes. [Tese], Universidade Federal de São Paulo - Escola Paulista de Medicina, São Paulo, 2002, 174p.

4. ISAAC Steering Committee. Worldwide variation in prevalence of symptoms of asthma, allergic rhinoconjunctivitis, and atopic eczema: ISAAC. The International Study of Asthma and Allergies in Childhood (ISAAC) Steering Committee. Lancet 1998; 351: 1225-32.

5. Solé D, Yamada E, Vana AT, Werneck G, Freitas LS, Sologuren MJ et al - International study of asthma and allergies in childhood (ISAAC): Prevalence of asthma and asthma-related symptoms among Brazilian schoolchildren. J lnvest Allergol Clin Immunol 2001; 11: 123-8.

6. Camelo-Nunes 1C, Wandalsen GF, Sole D - Asthma in Brazilian school-age children: a public health matter? J Pediatr (Rio J). 2003; 79: 472-3.

7. Boechat JL, Rios JL, Sant’Anna CC, França AT. Prevalência e gravidade de sintomas relacionados à asma em escolares e adolescentes no municipio de Duque de Caxias, Rio de Janeiro. J Bras Pneumol 2005; 2: 111-7.

\title{
Pursuing MEDLINE
}

JOSÉ ANTÔNIO BADDINI MARTINEZ ${ }^{(\mathrm{TE}}$ SBPT)

The MEDLINE system, sponsored by the United States National Library of Medicine (NLM) is the most important online database of scientific journals in the area of biomedicine. The system evolved out of the union of the Index Medicus, last published in 2004, and other, lesser, databases. Access to MEDLINE is available for free on the Internet, and the database is consulted daily by thousands of researchers and professionals in the areas of health and biological sciences. In these fields, there are approximately 14,000 journals in current publication worldwide. Of those, approximately 4800 are listed in MEDLINE(1).

The members of the Sociedade Brasileira de Pneumologia e Tisiologia (SBPT, Brazilian Society of Pulmonology and Phthisiology) have long hoped that the Jornal Brasileiro de Pneumologia (JBP, Brazilian Journal of Pulmonology) would be selected for indexing in MEDLINE. We are frequently asked when this will occur. To answer to this question, it is necessary to explain the process by which journals are evaluated by the NLM.
The decision as to whether or not a journal will be indexed in MEDLINE is ultimately made by the director of the NLM, based on advice given by the Literature Selection Technical Review Committee (LSTRC). The final decision should be made in accordance with the general policies adopted by the LSTRC, which are in turn dictated by the Board of Regents of the Library ${ }^{(2)}$. The LSTRC is composed of fifteen members, each affiliated with the National Institutes of Health, and meets three times per year. At every meeting, approximately 140 indexing requests, from journals the world over, are evaluated ${ }^{(1,2)}$. The committee analyzes the last four issues of each petitioning journal. On average, only 25 to $30 \%$ of the journals evaluated are selected for indexing.

The LSTRC evaluates a journal in various aspects $^{(2)}$ :

a. Scope and coverage: The journal should contain articles predominantly on core biomedical subjects. 
b. Quality of content: Scientific merit of the journal content is the primary consideration in selecting journals for indexing. Aspects such as originality of the articles, as well as the validity and importance within the field, are key factors in the selection of a journal.

c. Quality of editorial work: The journal should demonstrate features that contribute to the objectivity, credibility, and quality of its contents. These features may include information about the methods of selecting articles, especially on the explicit process of external peer review; statements indicating adherence to ethical guidelines; evidence that authors have disclosed financial conflicts of interest; timely correction of errata; explicit responsible retractions as appropriate; and opportunity for comments and dissenting opinion. Neither the advertising content nor commercial sponsorship should raise questions about the objectivity of the published material.

d. Production quality: Quality of the layout, printing, graphics, and illustrations are all considered in assessing a journal. Other considerations are the observance or nonobservance of established editorial guidelines, typographical errors, errors in grammar, standardization of bibliographic references, etc.

e. Types of content: Various types of journals are considered for indexing in MEDLINE. These different types include those whose contents consist of one or more of the following types of information: reports of original research; clinical observations; reviews; descriptions of methods; analysis of philosophical, ethical, or social aspects. Publications in which original article predominate are considered of greater importance and are selected more often than those containing only case reports. Journals will generally not be selected for indexing if the contents are subjects already well represented in MEDLINE.

f. Geographic coverage: Criteria for selection of foreign-language journals are the same as for those written in English. The highest quality and most useful journals are selected without regard for place of publication. In order to provide broad international coverage, highly-specialized journals published for a local audience have lower chances of acceptance. Special attention is given to research in general, as well as to studies in the areas of public health, epidemiology, standards of health care, and indigenous diseases.

After analysis, the LSTRC gives the journal a score from 0 to 5 . A score equal to or greater than 4 guarantees selection. Journals scoring between 2 and 3.99 are allowed a second review after two years, whereas those scoring less than 2 must wait three years for reanalysis. The waiting period between a second and third review is three years, regardless of the score received.

A careful reading of the list above reveals that the JBP currently meets nearly all of these requirements. However, some small details need to be attended to. More importantly, it is fundamental, albeit challenging, to maintain a consistent level of quality in the scientific content, editorial standards and printing. Such consistency will lend credibility to the journal and earn the respect of the international scientific community.

In order to win at a game, one must first learn to play the game. The rules of the game are clearly listed here above and will serve as our guide. Naturally, the final outcome of the game will often be influenced by imponderables. Nevertheless, dear friends, readers and JBP associates, what remains for us now is to don the shirt and sweat for our journal.

JOSÉ ANTÔNIO BADDINI MARTINEZ

Editor, Jornal Brasileiro de Pneumologia

\section{REFERENCES}

1. United States National Library of Medicine. Response to inquiries about journal selection for indexing at NLM. Available at: http://www.nlm.nih.gov/pubs/ factsheets/j_sel_faq.html [Accessed: 03/03/2005].

2. United States National Library of Medicine. Journal selection for MEDLINE. Available at: http:// www.nlm.nih.gov/pubs/factsheets/jselfaq.html [Accessed: 03/03/2005]. 